\title{
DELTA CURRENT CONTROL FOR VECTOR CONTROLLED PERMANENT MAGNET SYNCHRONOUS MOTORS
}

\author{
P. Freere, D. Atkinson, P. Pillay, Member, IEEE * \\ Dept. of Electrical Engineering, University of Newcastle upon Tyne, Newcastle upon Tyne. UK. \\ * Dept. Electrical Engineering, University of New Orleans, New Orleans, USA.
}

\begin{abstract}
To provide good torque control for a vector controlled permanent magnet synchronous motor (PMSM), delta current control can be used. It has the advantage compared to controllers such as hysteresis and ramp comparison, that the maximum switching frequency of the inverter transistors is predetermined. Although investigations into the delta controller have been performed, little work has been done on the characteristics of the controller and its influence on the inverter design. For the delta controller, the delta frequency must be chosen with respect to the required characteristics of torque, peak current and the average switching frequency of the inverter transistors. These characteristics are studied experimentally, using computer simulation and with mathematical analysis, with respect to the variables of delta frequency, dc supply voltage and the reference current magnitude. At low delta frequencies, there is an exponential increase in the mean torque and peak current. An approximate analytical expression is given to predict the delta frequency at which this operating region commences. The effect of the motor speed on the torque is shown to enable the minimum required supply voltage to be chosen and the upper bound on the delta frequency is shown to be determined by the maximum acceptable average switching frequency. Also investigated is the delta controller's transient response, torque harmonics, the effect of flux weakening and the effect of turn-off delays of the inverter transistors when bipolar darlington transistors are used as compared with IGBT's.
\end{abstract}

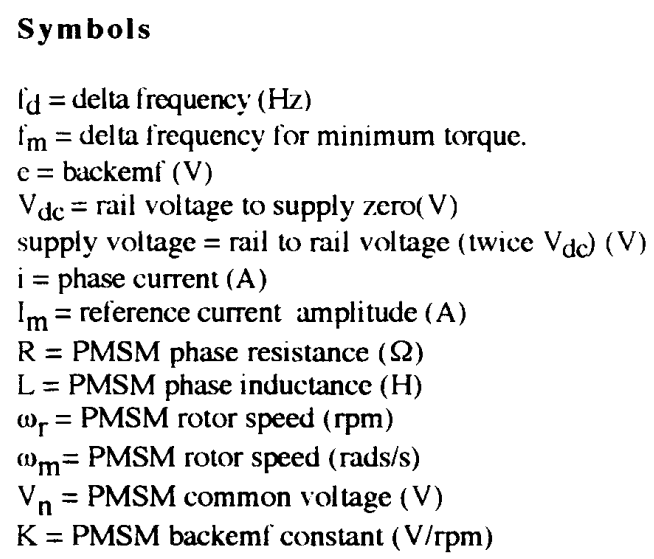

\subsection{Introduction}

Vector control of permanent magnet synchronous motors (PMSMs) [1] is used to provide the maximum torque per 0-7803-0634-1/92\$03.00 @IEEE amp [2] and a fast operating pertormance [3] by maintaining the stator field at $90^{\circ}$ spacially to the rotor field [4]. The vector control hardware has been implemented as shown in figure 1 [5], and the equivalent circuit of figure 2 [6] has been used as a basis for the computer simulations [7] and analytical results. The simulation takes into account the individual semiconductor device that is conducting in the inverter and its voltage drop. Unless specified, the simulations are based on a bipolar Darlington inverter transistor with a $10 \mu$ s storage delay time.

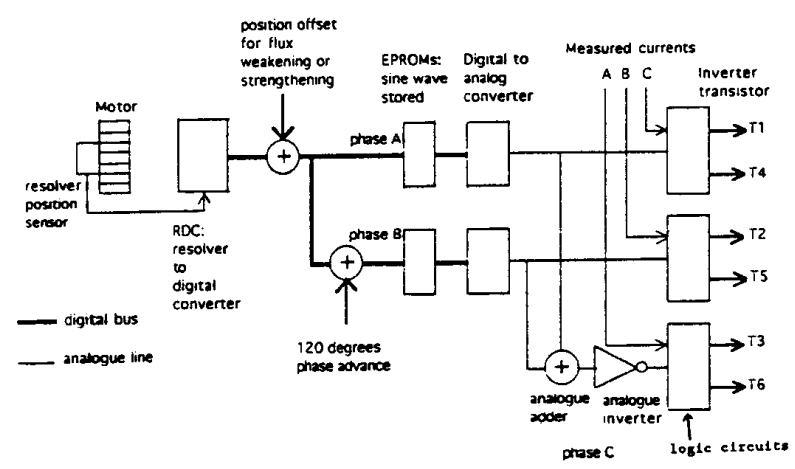

Figure 1. Vector control system.

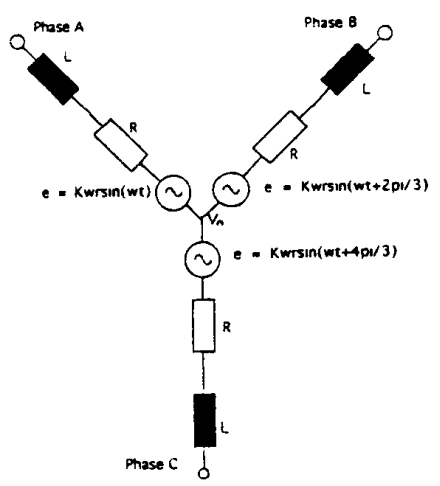

Figure 2. Equivalent circuit of the PMSM.

To provide a smooth torque [8], PMSMs require a sinusoidal phase current, which requires an inverter switching strategy such as the delta current control [9]. It combines an intuitively simple control strategy with a fixed maximum switching frequency [10][11], in contrast to the hystersis 
current controller which sulfers from a variable switching frequency during a period [12]. In order to assess the inverter requirements, the average inverter transistor switching frequency needs to be known as well as the peak phase current. The parameters of electric torque. average switching frequency and peak current are studied as functions of the delta frequency, reference current amplitude, supply voltage and motor speed.

The control strategy compares the actual current with the reference current at fixed sampling intervals (i.e. at the delta frequency) (figure 3 ), and the inverter is operated to change the sign of the current error. Although protection against the possibility of a shoot through fault can be attained by a turn on delay of the transistors [13], the protection has been implemented using the simpler approach of noncomplementary $[10]$ inverter transistor pair switching (see appendix).

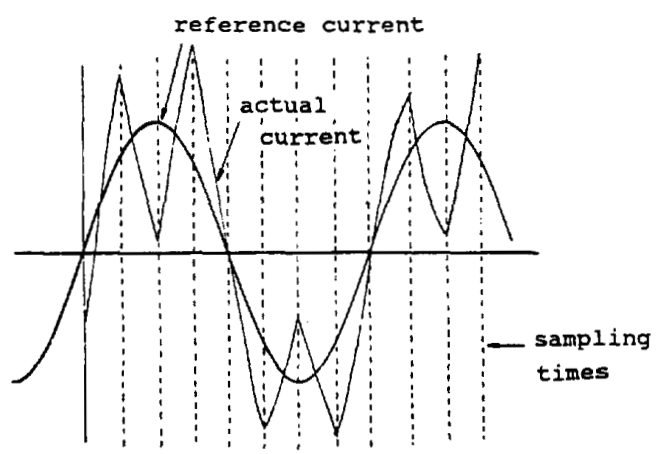

Figure 3. The principle of delta current control.

From the equivalent circuit, expressions can be developed for the current in each phase. For example, for phase $A$,

$$
\begin{aligned}
& V_{A}=R i_{A}+L \frac{d i_{1}}{d t}+e_{A}+V_{N} \\
& e_{A}=K \omega_{r} \sin (\omega t+\phi) \\
& i_{1}(t)=\frac{V_{1}-V_{V}}{R}+ \\
& -\frac{K \omega_{r}}{L\left[\left(\frac{R}{L}\right)^{2}+\omega^{2}\right]}\left\lceil\frac{R}{L} \sin (\omega t+\phi)-\omega \cos (\omega t+\phi)\right]+ \\
& +C e^{\frac{-R t}{l}}
\end{aligned}
$$
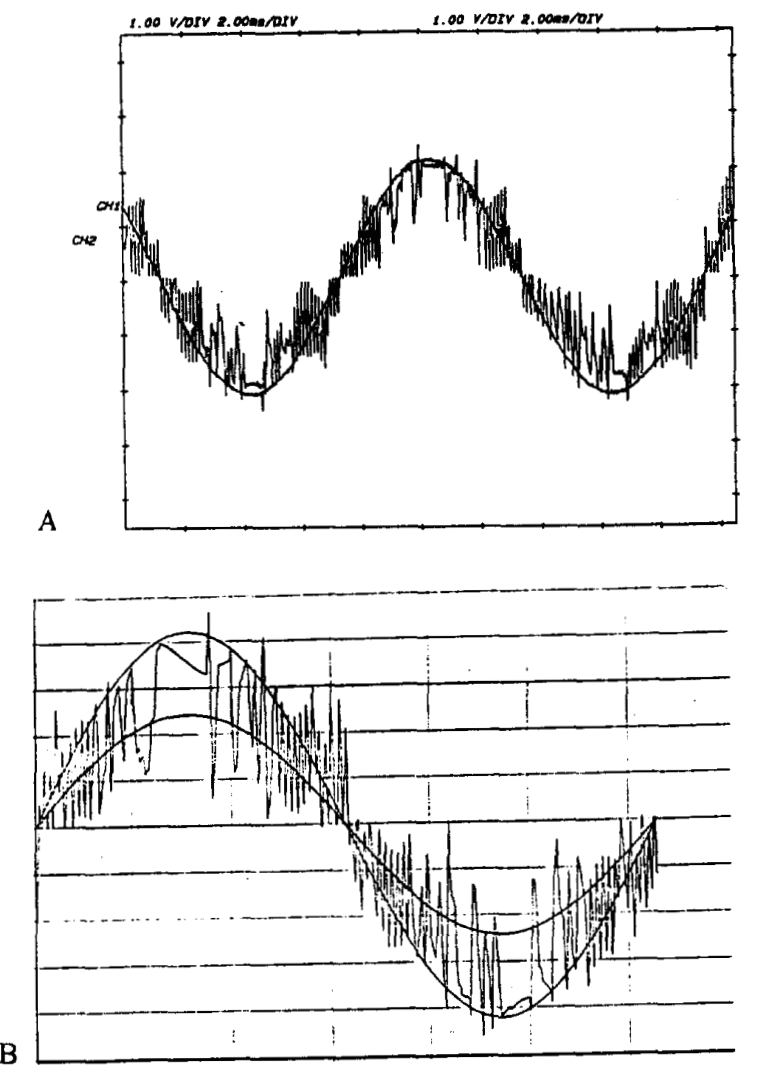

Figure 4. Delta current control with the motor as load A) experiment B) simulation.

where,

$$
\begin{aligned}
& C=e^{\frac{R t_{1}}{L}} \Gamma_{i_{1}}-\frac{V_{1}-V_{v}}{R}+ \\
& \frac{K \omega_{r}}{L\left[\left(\frac{R}{L}\right)^{2}+\omega^{2}\right]}\left[\frac{R}{L} \sin \left(\omega t_{1}+\phi\right)-\omega \cos \left(\omega t_{1}+\phi\right)\right] !
\end{aligned}
$$

\subsection{Delta Current Controller Characteristics}

\subsection{Torque Characteristics}

As the delta frequency approaches high values, the torque (figure 5) approaches a limit close to the required torque of $1.77 \mathrm{Nm}$ (see appendix for details).

As the delta frequency reduces, the torque reduces due to the effect that the backemf has in reducing the magnitude of the current slope away from zero, and increasing it towards zero, but below some value, the torque climbs exponentially. 
This is due to the low delta frequency allowing the current to reach zero betore it rises at the next delta instant. Below a particular delta frequency, as the current moves towards zero, it will remain at zero (an effect of the non-complementary switching) until the next delta instant. Hence, unlike the complementary switching case, the current always commences from zero and so rises further.

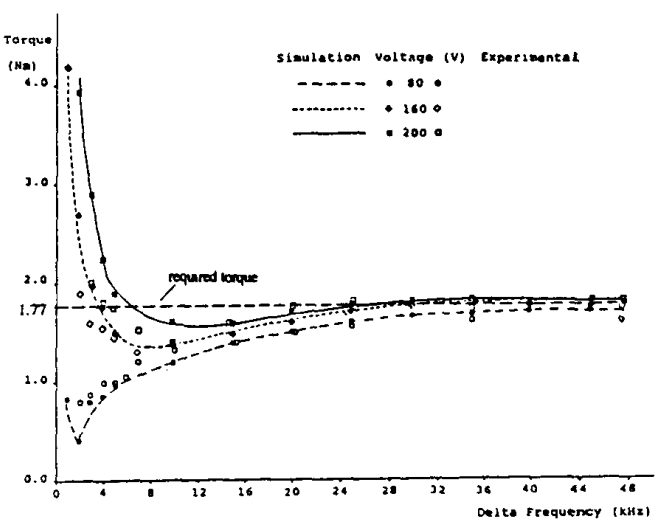

Figure 5. Torque versus delta frequency for various supply voltages. $\omega_{\mathrm{r}}=1230 \mathrm{rpm}, \mathrm{I}_{\mathrm{m}}=4.2 \mathrm{~A}$.

An approximate analytical expression can be derived for the delta frequency for the minimum torque. The torque will begin to rise as the delta frequency reduces, when between two delta instants, the current can rise to the maximum reference level. Due to the influence of the backemf, it will certainly hit zero before the next delta instant.

When the phase voltage is $V_{d c}$, the largest rise in the current occurs for $V_{N}=-V_{d c} / 3$. Although the equation for the current (3) can be numerically evaluated to determine the delta frequency at which the torque is a minimum. By assuming that the back emf remains constant during the delta frequency period, an analytical expression can be developed (5).

$$
f_{n}=\frac{1}{\left.-\frac{L}{R} \ln \mid \frac{\left.\frac{4}{3} V_{d c}-K \omega_{r}-I_{m} R\right\rceil}{\mid \frac{4}{3} V_{d r}-K \omega_{r}}\right\rceil}
$$

If in addition, the resistance is ignored, a simple relationship results;

$f_{m}=\frac{\frac{4}{3} v_{d c}-K \omega_{r}}{L I_{m}} \quad$ with $R=0$

By comparing experimental and analytical values for the delta frequency for minimum torque, there is reasonable agreement.

For a given delta frequency, the torque curve is at a constant slope with respect to the reference current amplitude. The variation of torque with speed (figure 6) shows a distinct comer speed at which the torque drops rapidly.

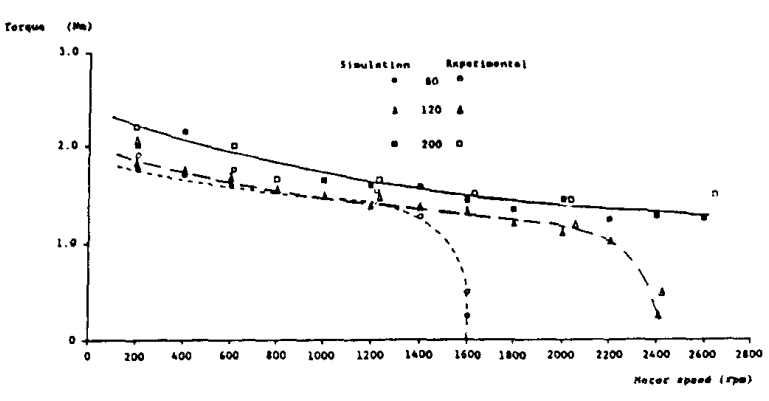

Figure 6. Torque versus motor speed for various supply voltages. $\mathrm{f}_{\mathrm{d}}=15 \mathrm{kHz}, \mathrm{I}_{\mathrm{m}}=4.2 \mathrm{~A}$.

As the supply voltage is increased, the corner frequency also increases, as does the torque.

\subsection{The Average Switching Frequency}

A transistor can be turned on at one delta instant and off at the next. Since the transistor only conducts over a half cycle, the maximum switching frequency of a transistor is one quarter of the delta frequency. Often the switching frequency is less as the current error does not change sign in the time between one delta instant and the next.

Figure 7 shows that the average switching frequency as a function of the delta frequency has an initially linear relationship, which approaches an asymptote as the delta frequency increases above $30 \mathrm{kHz}$. The divergence between the experimental and simulation results is related to the frequency limitation [14] of the Hall effect current sensors [15]. The average switching frequency increases with the voltage as the influence of the backemf is reduced.

Increasing the reference current amplitude reduces the average switching frequency due to the influence that the slope of the reference current has on the delta current control, requiring the current to take longer to cross the reference current waveform. The simulation agrees well at the lower delta frequencies, but at the higher delta frequency, the Hall effect current sensors limitations become clear.

As the speed of the motor increases, the backemf opposes the imposition of the supply voltage, which reduces the current control and hence both the torque and the average switching frequency reduce with the speed. The maximum average switching frequency occurs at zero speed and hence the maximum heat dissipation of the transistors can be determined. 
measured. The bipolar darlington transistor had a measured turn off time of $2.6 \mu \mathrm{s}$

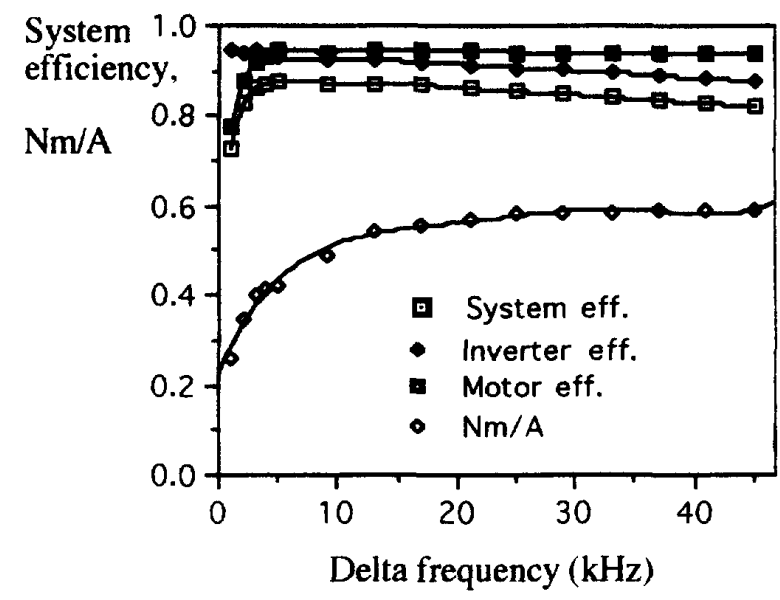

Figure 9 Simulation results of the motor, inverter and system efficiencies. $\omega_{\mathrm{r}}=1235 \mathrm{rpm}, \mathrm{I}_{\mathrm{m}}=4.2 \mathrm{~A}, \mathrm{~V}_{\mathrm{dc}}=60$.

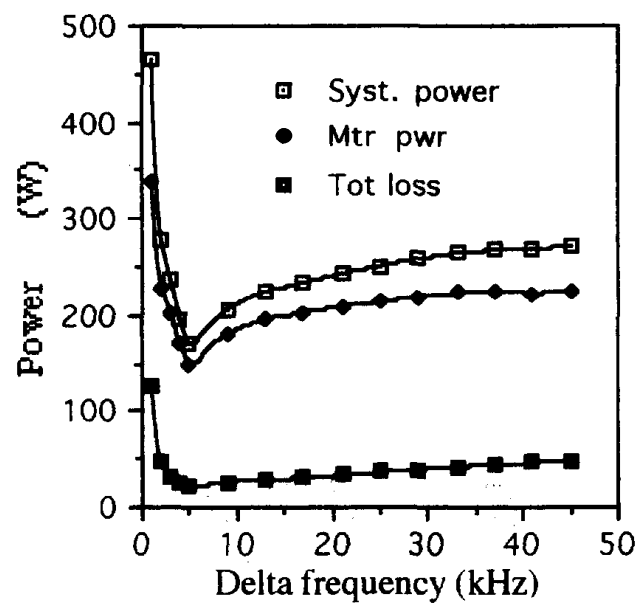

Figure 10 The system and motor power and loss as a function of the delta frequency. $\omega_{r}=1235 \mathrm{rpm} . \mathrm{I}_{\mathrm{m}}=4.2 \mathrm{~A}$. $v_{\mathrm{dc}}=60$.

and turn on time of $1.4 \mu \mathrm{s}$. Figure 11 shows the motor, inverter and system efficiencies when using the bipolar Darlington transistors or the IGBT's [17].The IGBT inverter losses are clearly much smaller than that of the bipolar Darlington inverter, and is significant in increasing the overall system efficiency. At the supply voltage of $120 \mathrm{~V}$, the average switching frequency does not increase above 6.5 $\mathrm{kHz}$, yet at a higher supply voltage, the switching frequency can be expected to reach one quarter of the delta frequency, and hence switching losses can be expected to increase. The losses can then be expected to be significant.

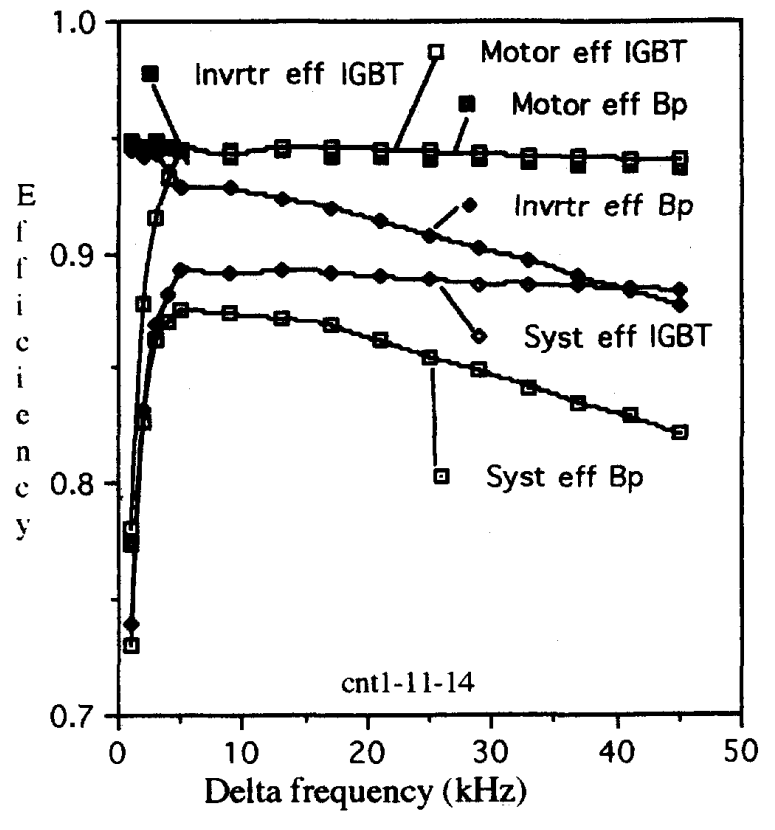

Figure 11. Comparison of the efficiencies of the bipolar darlington transistor inverter and IGBT inverter drives. $\omega_{\mathrm{T}}=$ $1235 \mathrm{rpm} . \mathrm{I}_{\mathrm{m}}=4.2 \mathrm{~A} . \mathrm{V}_{\mathrm{dc}}=60$.

The loss curve has a minimum at $5 \mathrm{kHz}$ delta frequency, but above this frequency it slowly increases. The motor power clearly increases more rapidly, but above $30 \mathrm{kHz}$ there is little gain.

\subsection{The Effect of Flux Weakening}

The maximum speed of the motor is limited by the dc supply voltage. As the motor speed increases, the back emf approaches that of the supply and the maximum speed is reached. The speed can be extended by flux weakening [18][19], thereby reducing the back emf. In a permanent magnet motor, flux weakening is achieved by altering the phase of the reference current with respect to the back emf. Then the peak back emf no longer corresponds to the peak of the reference current, hence enabling better current control (see figure 12).

Although flux weakening can be applied at motor speeds where good current control exists, there is no advantage and the torque will decrease. Because the flux weakening decreases the current harmonics, it will also decrease the torque harmonics (figure 13).The speed range is extended significantly, since the torque available has increased due to the extra current control.

\subsection{Torque Response}

For a supply voltage of $120 \mathrm{~V}$, the electric torque response at a delta frequency of $20.3 \mathrm{kHz}$ is shown in figure 14 , for a step inrcease in the commanded torque from zero to full 
torque for the PMSM with a locked rotor.

A

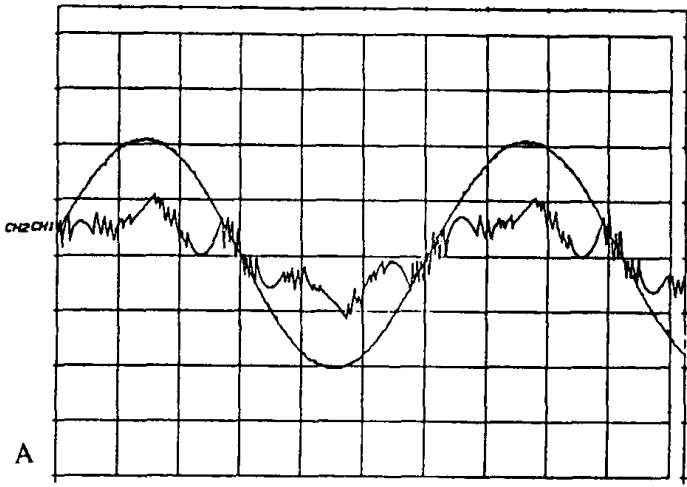

B

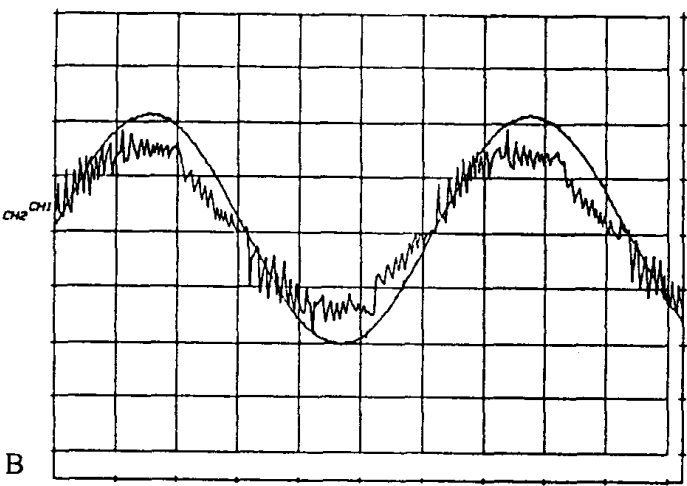

Figure 12 Experimental current waveforms A) without flux weakening, $B$ ) with flux weakening. $V_{d c}=60 \mathrm{~V}, \omega_{r}=2350$ rpm, $\mathrm{I}_{\mathrm{m}}=4.2 \mathrm{~A}$.

The step torque response results in a very rapid rise in torque over a time period of $250 \mu$ s. There is an initial delay of .50 $\mu s$ corresponding to the time between delta samples. Figure 15 shows that there is no torque overshoot. For a rapid torque step response, it is necesary to ensure that the delta period is small compared to the rise time of the phase currents from zero to their rated value.

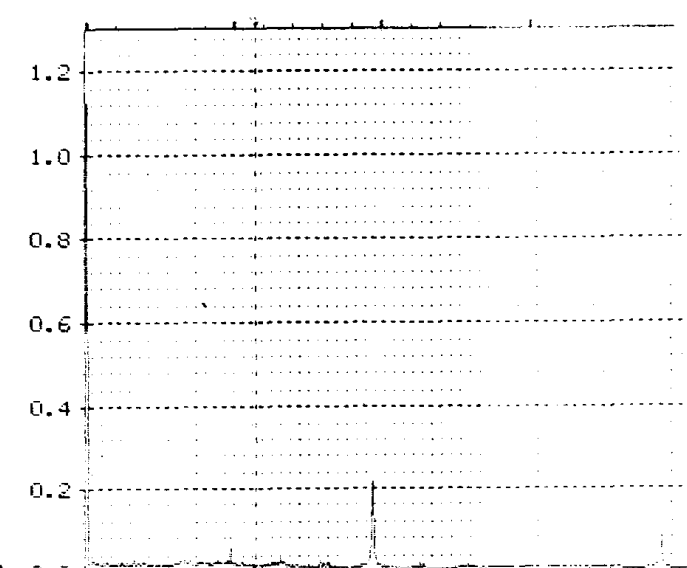

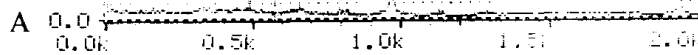

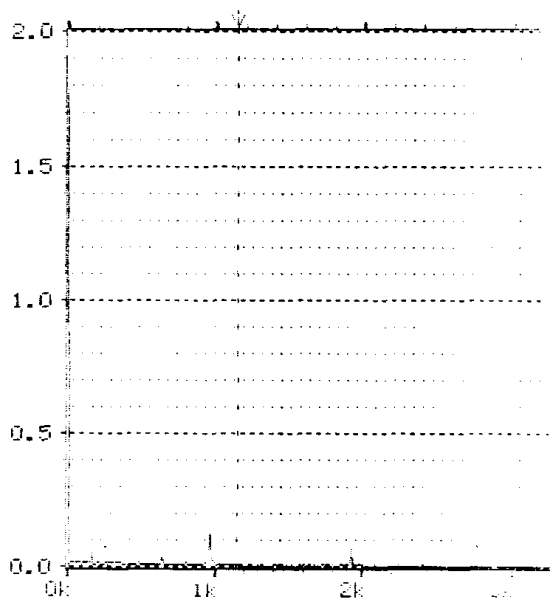

Figure 13. Fourier spectrum of the torque A) without flux weakening, B) with flux weakening. $V_{d c}=60 \mathrm{~V}, \omega_{\mathrm{r}}=2350$ $\mathrm{rpm}, \mathrm{Im}_{\mathrm{m}}=4.2 \mathrm{~A} .1$ torque unit $=0.6186 \mathrm{Nm}$.

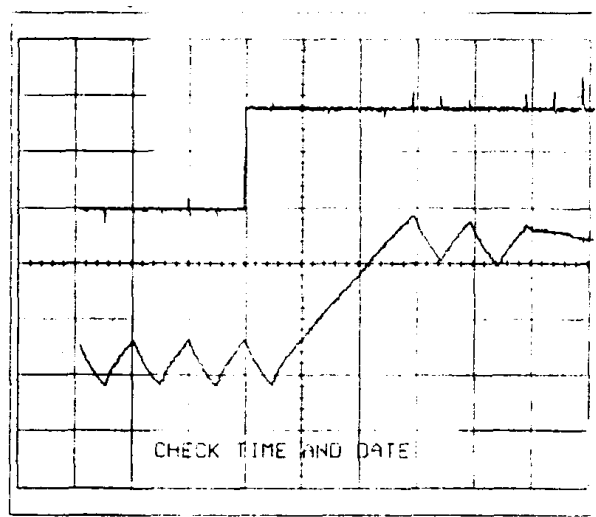

Figure 14. Electric torque (as measured by the electronic torque estimator) for a step torque response. $100 \mu \mathrm{s} / \mathrm{div}$. 


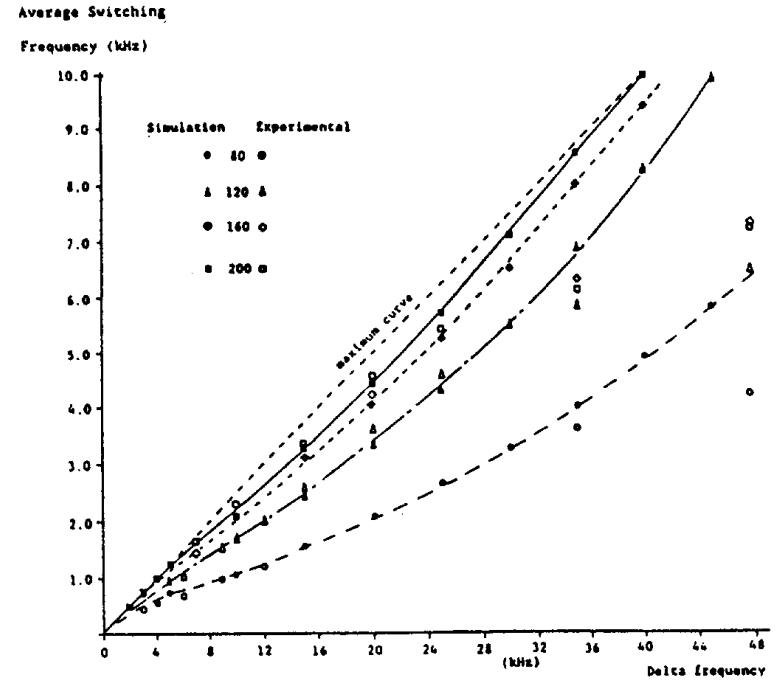

Figure 7. Average inverter transistor switching frequency versus delta frequency for various supply voltages. $f_{d}=15$ $\mathrm{kHz}, \mathrm{I}_{\mathrm{m}}=4.2 \mathrm{~A}$.

\subsection{The Peak Current}

When designing the inverter it is necessary to know the peak current, since there is no direct control of the current magnitude. If the delta frequency is too low the current can reach large magnitudes. An upper bound to the current magnitude can be determined by assuming the maximum rate of current rise for the length of time in the delta interval. The peak current is dependent on the initial value of the current, which in the worst case is the reference current maximum. An analytical solution can be found if the backemf and reference current are considered to be constant in the del ta interval, that is;

$$
\begin{aligned}
& \text { (3) } \quad i_{\text {peak }}= \\
& \frac{\frac{4}{3} V_{d c}-K \omega_{r}}{R}-c^{-(R / t d L)} \frac{\frac{4}{3} V_{d c}-K \omega_{r}-I_{m}}{R}
\end{aligned}
$$

The good agreement between the measured and calculated values of the peak current of figure 8 allows the calculated values to be used to provide the maximum current rating for the inverter.

\subsection{The Motor and Inverter Efficiency}

The system power is defined as the power entering the inverter, whereas the motor power is defined as the total power entering the motor, comprising the electrical motive power and the losses. The total loss is the difference between the motive power and the power supplied to the inverter. With the motor used, no hysteresis, eddy current or magnetic saturation losses could be measured. Therefore the major loss is only resistive, which is proportional to the square of

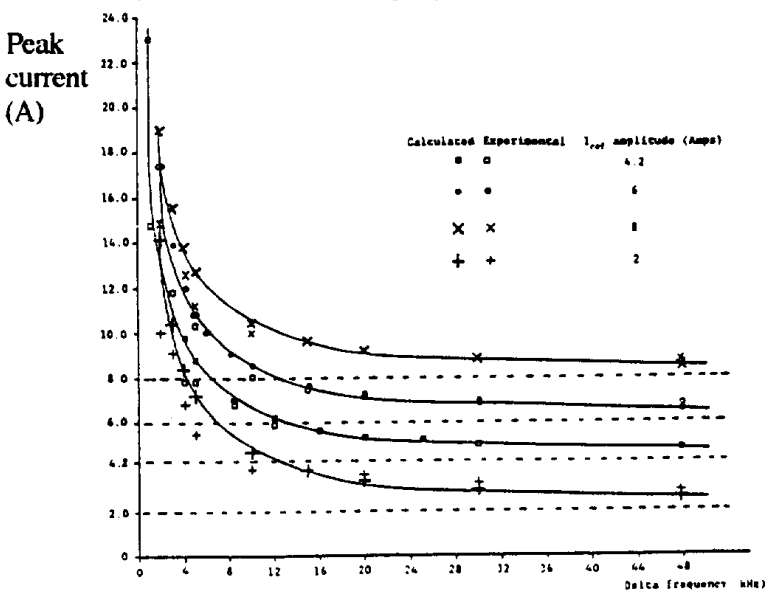

Figure 8. Peak phase current versus delta frequency for various reference current amplitudes. $v_{d c}=60, \omega_{r}=1230$ rpm.

the current. At low delta frequencies, the current tends to rise well above the amplitude of its fundamental, hence the losses are large for the torque produced. As the deita frequency increases, the ratio between the peak currents and the fundamental amplitude decreases, and the efficiency of the motor improves.

The inverter losses are composed of conduction losses and switching losses. Apart from at very low switching frequencies, the majority of the losses are switching losses, and hence the inverter efficiency reduces as the switching frequency increases.

Maximum efficiency of the motor drive system is affected by both the motor and inverter efficiencies. Due to experimental difficulties, direct measurement of losses was not possible, however, simulation results are presented in figure 9.

Figure 9 shows that the maximum system efficiency occurs near $5 \mathrm{kHz}$ delta irequency, although the maximum torque/Amp occurs at a much higher delta frequency. After the first $5 \mathrm{kHz}$, the motor efficiency remains quite constant as the current is quite close to the reference waveform, but the inverter efficiency continues to decline as its switching frequency increases. By looking at the power curves (figure 10), at low delta frequencies, the losses are large, but above $30 \mathrm{kHz}$, there is little to be gained in increasing the delta frequency further. Operation at frequencies above $40 \mathrm{kHz}$ will place the fundamental frequency of the audio noise of the current control above the hearing range.

When using an IGBT, a slightly higher voltage drop of 2.5 $V$ was assumed for the simulation, in comparison with 2.4 $\mathrm{V}$ for the bipolar darlington transistor [16], but a much faster turn on and off time of approximately $80 \mathrm{~ns}$ was 


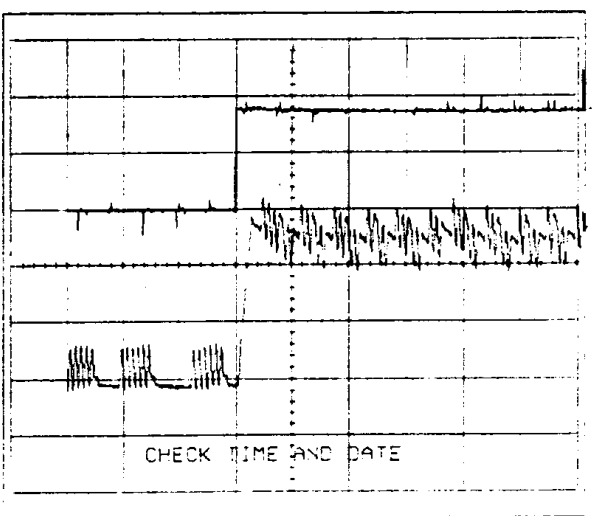

Figure 15. Electric torque (as measured by the electronic torque estimator) for a step torque response. $1 \mathrm{~ms} / \mathrm{div}$.

\subsection{The Effect of the Turn-off Delay}

The storage delay of the bipolar Darlington transistors ensures that the transistor remains on after the base goes low. The effect is that the current will increase in magnitude, and hence the total torque produced will increase. Simulation results are shown in figure 16 . The simulation also showed that there is a $12 \%$ increase of the average switching frequency with $20 \mu$ s turn off delay compared to with no turn off delay.

\subsection{Conclusion}

The delta current characteristics have been examined to allow design guidelines for the inverter to be formulated. Because of the good agreement between the experimental and simulation results, the equivalent circuit model of the motor has been validated and can be used to choose the inverter parameters. An analytical expression for the minimum delta frequency for good torque control has been developed, as has an equation to determine the peak current rating required for the inverter. The required thermal rating of the inverter can be calculated from the delta irequency at zero motor speed with the rated current through the inverter transistor. The supply voltage can be determined from the maximum motor speed required. The inverter used fast bipolar darlington transistors with a $10 \mu$ s turn-off delay, which affects the controller operation. The effects of the turn-off delay have been examined and has been shown that it increases the torque.

\section{Torque $\mathrm{Nm}$}

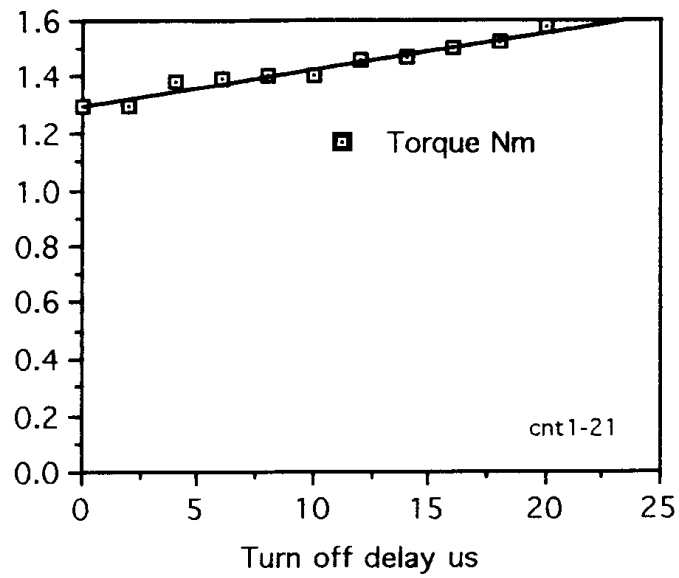

Figure 16. Electric torque as a function of the turn off delay.

\subsection{Appendix}

\subsection{Switching Loss}

As a conducting transistor turns off, the voltage across it is assumed to change instantaneously from $V_{c e(s a t)}$

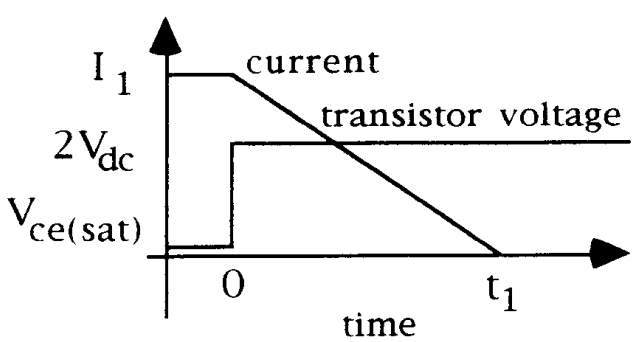

Figure 17. Transistor current and voltage during turn off.

to the full rail voltage, whereas the current falls linearly to zcro (figure 17). The turn off energy dissipated in the time $t_{1}$ is:

$$
\int_{0}^{4} i(t) v(t) d t=V_{d c} I_{1} t_{1}
$$

The average power dissipation is then;

$$
\frac{V_{d c} I_{1} t_{1}}{t_{1}}=V_{d c} I_{1}
$$

This equation applies for both the turn on and turn off situation. 


\subsection{Electronic Torque Estimator Board}

Since it is difficult to measure the shaft torque harmonics directly due to the inertia of the system and the frequency response of the torque transducers, an electronic circuit has been developed which multiplies the measured phase currents with the stored back $\mathrm{emf}$ waveform corresponding to each phase. The signals from the three phases are then summed to give a signal proportional to the instantaneous electric torque. This signal can be analysed with a Fourier signal analyser to give the torque harmonic spectrum.

\subsection{Non-complementary inverter transistor switching.}

If the current is not in the process of changing sign, the current in a phase of the motor is being carried by either a transistor or diode of the corresponding inverter leg. At no stage do both transistors conduct. A common approach is that as one transistor is turned off the other is tumed on (and visa versa). In general transistors turn on more quickly than they turn off, hence there is a danger that a shoot through fault will occur. A protection method is to apply a tum on delay, but this interferes with the current control and also the length of the turn on delay required is transistor dependent. An alternative protection method is that of noncomplementary switching, in which only the inverter transistor corresponding to the sign of the reference current is switched. That is, if the reference current is positive, only the upper inverter transistor will be switched. The other transistor of the same inverter leg is not turned on during that reference current half cycle.

\subsection{Motor Parameters}

$\mathrm{L}=1.6 \mathrm{mH}$

$\mathrm{R}=0.7 \Omega$

$K=0.0294$

\subsection{Motor Torque}

The required motor torque can be determined directly from the reference current amplitude and motor speed.

$$
\begin{aligned}
\text { Required torque }=3 \mathrm{i}_{\mathrm{rms}} & \mathrm{e}_{\mathrm{rms}} \frac{1}{\omega_{\mathrm{m}}} \\
& =0.0441 \mathrm{I}_{\mathrm{m}} \omega_{\mathrm{r}} \frac{1}{\omega_{\mathrm{m}}} \\
& =0.421 \mathrm{I}_{\mathrm{m}}
\end{aligned}
$$

\subsection{References}

[1] G. Liu, W. G. Dunford, "Comparison of simusoidal excitation and trapezoidal excitation of a brushles permanent magnet motor", Proc. IEE Power Electronics and Variable Speed Drives Conf. 1990, pp 446 - 449.

[2] M. Rahman, "Permanent magnet synchronous motors - a review of the state of the design art", proc. Int. Conf on
Electrical Machines, Athens, 1980, pp 312 - 319.

[3] T. Low, et al., "Permanent magnet motors for brushless operation". IEEE transactions on Industrial Aplications, Vol. 26, no. 1, Jan. 1990, pp 124 - 129.

[4] T. Sebastian, G. Slemon, "Operating limits of inverterdriven permanent magnet motor drives", IEEE IAS Annual Meeting, 1986, pp 800 - 805.

[5] P. Freere, P. Pillay, "Systematic design of a permanent magnet synchronous motor drive", Proc. Industry Applications Soc.: Annual Meeting, 1990.

[6] A. Wallace, R. Spee, "The effects of motor parameteres on the performance of brushless dc drives". Proc. IEEE IAS Annual Meeting, 1987, pp 591 - 597.

[7] P. Evans, D. Brown, "Simulation of brushless dc drives", Proc. IEE, vol 137, Pt B, no. 5, Sept. 1990, pp $299-308$.

[8] P. Sen, "Electric motor drives and control - past, present and future", IEEE Transactions on Industrial Electronics, vol. 137 , no. 6 , pp 562 - 575.

[9] R. Lorenz, D. Divan, "Dynamic analysis and evaluation of delta modulators for field orientated ac machine current regulators", Proc. IEEE IAS Annual Meeting, 1988, pp 196 - 201.

[10] P. Freere, P. Pillay, "Design and evaluation of current controllers for PMSM drives", IEEE IECON'90, 1990, pp $1193-1198$.

[11] X. Xu, D. Novotny, "Bus utilization of discrete CRPWM inverters for field oriented drives", IEEE IAS Annual Meeting, 1989, pp 362 - 364.

[12] E. Gafo, R. Piovan, L. Malesani, "Comparative analysis of hysteresis modulation methods for VSI current control", IEE Machines and Drives Conference, 1988, pp $336-339$.

[13] Y. Murai, T. Watanabe, H. Iwasaki, "Waveform distortion and correction circuit for PWM inverters with switching lag-times", IEEE IAS Annual Meeting, 1985, pp 436 - 441 .

[14] T. Sonoda, R. Ueda, K. Koga, "A sensor of high accuracy fit for precise and exact motion control", Proc. IEEE IÁS Annual Meeting, 1989, pp 343 - 347.

[15] K. Butler, A. Selcuk, "Halleffect current transducers", Proc. IEE Drives Machines and Control Conference, 1984, pp $203-208$.

[16] P. Maugest, "Power transistors and darlington: special requirements for motor drive", proc. IEE Dives, Machines and Control Conference, 1984, pp 182 - 187.

[17] P. Eschrich, "Protection of IGBT modules in inverter circuits", EPE Journal, vol. 1, no. 1, July 1991, pp 57 - 60. [18] S. Morimoto et al., "Expansion of operating limits for permanent magnet motor by optimum flux weakening", IEEE IAS Annual Meeting, 1989, pp $52-56$.

[19] T. Jahns, "Flux weakening regime operation of an interior permanent magnet synchronous motor drive". IEEE IAS Annual Meeting, 1986, pp 814 - 823. 